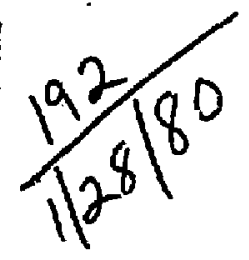

JAINUARY 1980

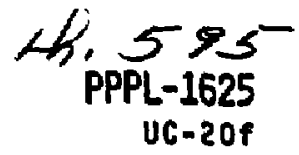

\title{
DISSOCIATIVE EXCITATION AS THE SOURCE OF NEUTRAL ATOMS IN HYDROGEN DISCHARGES
}

\section{MASTER}

BY

D. H. MCNEILL

\section{PLASMA PHYSICS LABORATORY}

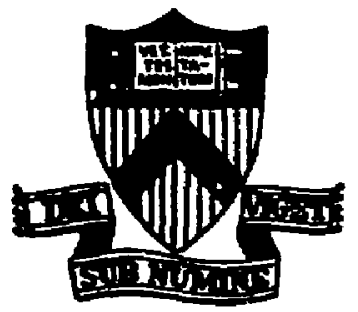

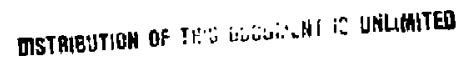

\section{PRINCETON UNIVERSITY PRINCETON, NEW JERSEY}

This work ras supported by the 0 . S. Departaent of Energy Cuncract No. ET-76-C-02-3073. Reproduction, translation, publlcetion, use and disposal, in whole or in part, by or for the tuited states Govermint is permitted. 
DISSOCIATIVE EXCITATION AS THE SOURCE OF NEUTRAL ATOMS IN HYDROGEN DISCHARGES

D. H. MaNe 111

\begin{abstract}
Electron impact dissoclative excitation of $\mathrm{H}_{2}$ molecules is identified as the origin of the narrow width and structure of Balmer lines observed in various low density hydrogen discharges. On the basis of this data and estimates of the rates of competing processes in plasmas, aissociative excltation, together with other molecular reactions, is proposed as the source of neutral atoms and protons in these discharges.
\end{abstract}

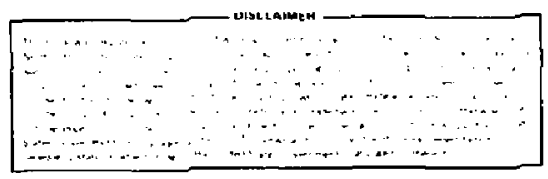

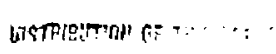


The manner in which hydrogen atoms enter a discnarge is of fundamental importance in basic discharge physics and fusion research. The low energy neutral atoms observed spectroscopically in hydrogen dischaxges are often assumed to have undergone wall recycling (as atoms) and energy degradation. In certain discharges the Balmer alpha and beta lines always have half widths of less than $0.5 \&$ that vary little with the discharge and plasma parameters. The shape of the profile in the wings, however, does vary with the electron temperature. Here I offer dissociative excitation of gaseous phase molecular hydrogen as an explanation for the narrow width and structure of the Balmer Jines and (together with similar reactions of $\mathrm{H}_{2}^{+}$ions) as a source of the "fresh" neutral atoms and protons in these discharges. This explanation is consistent with data on the $\mathrm{H}_{\alpha}$ spectrum from ion sources for neutral beam injectors and from the Elmo Bumpy Torus and may help solve numerous problems in the pnysics of these other discharges. A brief discussion is given of the processes by which $\mathrm{H}$ atoms and $\mathrm{H}^{+}$ions are produced in the plasma volume. While more detailed analysis is clearly needed, the role of dissociam tive excitation in the production of protons and atoms in these plasmas is supported by rough estimates of the volume rates for various relevant processes as well as by the spectroscopic data. Electxons striking a neutral hydrogen molecule may cause several reactions. The pruncipal reactions of this type are Iisted in Table 1 with their electron onset energies. The mast important of these reactions are molecular dissociation (referred 
to as dissociative excitation if a product atom is excited the terms are often used interchangeably) and molecular ionization. The product $H$ atoms from reactions (1) and (3) and from electron impact dissociation of the $\mathrm{H}_{2}^{+}$lons formed in reaction (2) may be excited and it is these which are observed spectroscopically. The two onset energies given for molecular alssociation correspona to the measured onset energies for molecular dissociation (without excitation) il] and for dissociative excitation to the $H(n)$ state $(n \geqslant 2)[2,3]$, respectively. The onset energy given for reaction (3) is for an unexcited product atom and excitation may occur at nigher electron energies. The cross sections for reactions (1), (2), and (3) are plotted as functions of the electron energy in Fig. $1[1,4,5]$. (The crogs section for reaction (4) with cold $\mathrm{H}_{2}$ is negligibly small. on this scale.) Protons are formed in further reactions with the products of reactions (1) and (2). In particular, electron impact dissociative excitation and dissociative recombination of the molecular ion formed in reaction (2) have very large cross sections so reaction (2) may be followed quickly by the formation of protons and neutral atoms. Reaction ( 1 ) is folluwed by electron ionization or by charge exchange of the atoms to yield protons.

$$
\text { Dissociative excitation yields } \mathrm{H} \text { atoms in two energy groups }
$$
(first measured in 1967 by Leventhal, Roblscoe, and Lea) [2] : slow (atom energies $\mathrm{E} \sim 0.3 \mathrm{eV}$ for electron energies $E_{\mathrm{e}} \geqslant 15-18 \mathrm{eV}$ ) and fast $\left(\mathrm{E}_{\sim} 2-8 \mathrm{eV}\right.$. for $\mathrm{E}_{\mathrm{e}} \geqslant 28 \mathrm{ev}$; the customary Franck-Condon energy). These energy groups have been examined in electron beam experiments by botn time-of-tlight and spectroscopic techniques. Figure 2 shows some experimental energy spectra of 
fast and slow $\mathrm{H}(2 \mathrm{~s})$ atoms produced by dissociative excitation of $\mathrm{H}_{2}$ molecules (solid curves) [3] compared with Maxweltian energy distributions having the same most probable energies (dashed curves). The data of Fig. 2 (a) and (b) were taken for $E_{e}=80 \mathrm{eV}$ and $40 \mathrm{eV}$, respectively, and in both cases the metastabLe $\mathrm{H}(2 \mathrm{~s})$ itoms were detected at an angle of $80^{\circ}$ to the electron beam. The peaks of the energy distributions of the product atoms shift slightly to higher energies as $\mathrm{E}_{\mathrm{e}}$ is increased [3]. Both fast and slow dissociation products have been observed during bombardment of $\mathrm{H}_{2}$ gas with electrons at energies of up to $1000 \mathrm{eV}$ (dissuciative lonization, in practice a special case of dissociative ionization, dominates for $E_{e} \geqslant 60 \mathrm{eV}$ ). Other reactions (including dissoclation of $\mathrm{H}_{2}^{+}$, dissociative ionization of $\mathrm{H}_{2}$, and photoionization of $\mathrm{H}_{2}$; besides dissociative excitation of $\mathrm{H}_{2}$ have been found experimentally to yield atoms or protons in the 2-12 eV energy range, although, to the best of my knowledge, the slow group has not been looked for except in the case of dissociative excitation and dissociative ionization of $\mathrm{H}_{2}$. Thus, several processes may contribute to (at least) the fast atom component observed in plasmas. Figure 3 shows the kinetic energy speatra of the fast products in four cases $[3,6,7]$. The bulk of these energy spectra lie in the range $2-8 \mathrm{eV}$. (Since the rate of dissuciative ionization of $\mathrm{H}_{2}$ is small compared with competing protonproducing processes, the contribution of, for example, curve 4 of Fig. 3 to the overal.1 atom energy distribution in plasmas will be relatively small.) 
The existence of these two groups of disgociation products explains well the spectroscopic observations which I shall now discuss. The treasurements were made on the Elmo Bumpy Torug (EBT) and on neutral beam injec'ur ion sources. EBT is a steady state microwave-heated (up to $60 \mathrm{~kW}$ in the experiments reported here) toroidal device with a major radius of $150 \mathrm{~cm}$ and a minor radius of $25 \mathrm{~cm}$ (at the observation point) [8]. The lon sources are low-density pulsed ( $\leqslant 200 \mathrm{msec}$ ) arcs with dimensions on the order of $25 \mathrm{~cm} \mathrm{[9].} \mathrm{Table} 2$ illustrates some of the cases examined on these devices and lists the discharge conditions and $\mathrm{H}_{\alpha}$ spectrum data for each. Raw data from Fabry-Perot interferometer traces obtained in each of the regimes listed in this table are plotted in Fig. 4. From the bottom to the top of Fig. 4 there is a rough progression from low to high electron temperatures. The widths of the fast (where it exists) and, especially, the slow components appear to be invariant under al1 conditions. In the EBT data the ratio of the areas of the slow ind fast (where it exists) components ranges roughly from 1 to 3 when the fill pressure and other conditions are varied (the fast component may be absent at pressures corresponding to the transitions between modes, as it is at high pressures). The energies associated with these Doppler widths correspond to the energies of the product atoms found in dissociative excitation of the hydrogen molecule $[2,3]$, and no narrower spectral component (as is seen in much smaller and colder discharges) which might correspond to the wall temperatures is found in these data. 
In the dense fill microwave discharge on EBT (case F) there is no fast (wide) $H_{\alpha}$ component (down to less tnan 28 of the peak intensity). This is an indication of a low electron temperature. For example, In a plasma with an electron temperature $\mathrm{T}_{\mathrm{e}}=4 \mathrm{eV}, 38$ of the electrons have $\mathrm{E}_{\mathrm{e}} \geqslant 18 \mathrm{eV}$ and are able to participate in disgoclative excitation to yleld the $n=3$ state of hydrogen, and of these (the 38 ), 98 have $E_{e}>28.5 \mathrm{ev}$ and are capable of producing the fast dissociation component. Thus, for $\mathrm{T}_{\mathrm{e}}=4 \mathrm{eV}$, roughly 4.58 of the excited product atoms belong to the fast group (assuming that half of the atoms produced by electrons with energies above $28.5 \mathrm{ev}$ are in each group). The $H_{\alpha}$ emission $1 \mathrm{~s}$ most intense in this case $(F)$ and, as many low temperature microwave discharges are, the plasma is evidently a rich source of $H$ atoms. The inn source discharges (cases $E$ and $D$; also with low temperatures [9]) also have only a slow component. [A slow atom energy spectrum of the form given in Fig. 2 (a) yields an $H_{\alpha}$ spectrum of the form shown in FIg. 4 (d, e, and $f)$ when the instrument profile (Airy function) of the interferometer is included.] The other, lower pressure operating regimes of EBT (the $T$ mode, our case $A$, is the typical operating regime of this device) have significantly higher electron temperatures (measured by Thomson scattering) and both groups of atoms show up in the spectrum. [The straight line fits in curves $a, b$, and $c$ of Fig. 4 do not necessarily ir.licate a thermal energy distribution of the Fast component for $\Delta \lambda^{2} \leqslant 0.2 \AA^{2}$, as a fast component energy distribution with a low energy cutoff, as in Fig. 2 (b), will have a flat spectral distribution for $\Delta x$ smaller than the Doppler shift 
corresponding to the cutoff.l Thus, as the electron temperature goes above a few $\mathrm{eV}$, a fast atom component d tars, while at low ' ${ }^{e}$ only the slow component is observed.

At low $T_{e}$ nearly all the atoms (and protons) in the discharge should be due to molecular dissociation [reaction(1)] which yields protons upon ionization of the product atoms, rather than to molecular Ionization [reaction (2)]which is followed by further electron impact reactions to produce both atoms and protons. For example, when $\mathrm{T}_{\mathrm{e}}=2 \mathrm{eV}$ the rates for reactions (1) and (2) are $3 \times 10^{-10}$ and $-6 \times 10^{-12} \mathrm{~cm}^{3} / \mathrm{sec}$, regpectively, while when $T_{e}=4 \mathrm{eV}$ the corresponding rates are $3 \times 10^{-9}$ and $4 \times 10^{-10}$ $\mathrm{cm}^{3} / \mathrm{sec}$. The rates for these two reactions are equa $\perp\left(\sim 1 \times 10^{-8}\right.$ $\mathrm{cm}^{3} / \mathrm{sec}$ ) when $\mathrm{T}_{\mathrm{e}}-12 \mathrm{ev}$, after which reaction (2) proceeds more rapidly. Whether reaction (1) alone or reaction (2) followed by other processes is the origin of most of the $\mathrm{H}$ atoms in a discharge thus depends primarily on the plasma electron temperature. Which of thege two reactions is the dominant source of protons in the volume of a plasma is also determined by the mean free path for the succeeding proton-producing reactions (i.e., by the electron density as well as by the electron temperature) and by the plasma volume. In ganeral, for a given electron density, the larger the plasma rolume is, the lower the temperature above which the chain starting with reaction (2) becomes the dominant source of protons. In a very small $(\leqslant 1 \mathrm{~cm})$, cold discharge, wall reflections of $\mathrm{H}$ atoms produced by molecular dissociation will become important as a source of excited atoms and protons in the discharge (even if the reflection coefficient for atoms is smal1) as is indicated by the much narrower $\mathrm{H}_{\alpha}$ linewidth seen 
in low density discharges of this type, apparently as a consequence of equilibration with the vegsel walls.

Assuming a uniform distrubution of the electron density and temperature and of the molecular density in the discharges of cases D, E, and F, it can be shown that the rate of $H_{\alpha}$ production by dissoclative excitation is at least comparable to the observed average volume emissivity from the more complete analysis, incluaing the variations in the plasma parameters across the discharge chamber is obviously needed for these and the other cases. However, the facts that the observed intensity and line shape can be explained in terms of the reaction rate and product energy spectrum of dissoclatıve excitation and that there is no energy component in the $\mathrm{H}_{\alpha}$ spectra which corresponds to reasonable values of the wall temperature support the idea that volume processes involving $\mathrm{H}_{2}$ molecules which enter the discharge as feed gas or from the walls (as molecules, not atoms) are responaible for the atoms and ions in the duscharge.

At the dissociation energies (about 0.3 and $3 \mathrm{ev}$ ), product atoms in the $n=2(p), 3$, and 4 states will, emit photons over a mean free path of less than $1 \mathrm{~cm}$ so they will be observed near where they are produced. In the plasmas discussed here, the mean free path for ionization of the atoms (slow or fast) produced by dissociative excitation is comparable to or greater than the plasma dimensions. Thus, the neutral density profile must be fairly uniform. In much hotter and denser plasmas such atoms will exist only near the edge and a much faster chargechange neutral component may produce significantly larger Doppler widths tnan seen in this data. The slight difference between the 
widths of the slow component for the ion sources and for the EBT discharges is due to zeeman splitting in the 2-5 kG magnetic field in the viewing volume of EBT. This suggests that some of the hycrogen Balmer line proflles obtained from hotter, denser, and higher-magnetic-field plasmas can be interpreted in terms of these dissociation componentg and the itark or zeeman broadening of their line emission.

2 made these measurements of $H_{\alpha}$ protiles on the neutral beam $i r_{i j e c t o r}$ ion sources and EBT some years ago at OKNL. The observed narrow linewidths can now be explained consistently. Evidence for the occurrence of dissoclative excitation of $\mathrm{H}_{2}$ includes the appearance of neutral atoms with energles of about $0.3 \mathrm{eV}$ over all the observed discharge regimes (fill pregsure, magnetic field, electron temperature, wall conditions, heating mechanism, etc.), the existence of large amounts of neutral hydrogen molecules in the discharges $\left(H_{2}\right.$ line spectrum), and the appearance of a fast neutral atom component with an energy of about $3 \mathrm{ev}$ at higher electron temperatures. Furthermore, based on rough estimates of the rates of the processes involved, these discharges are large enough to ensure that volume effects dominate. Thus, in these plasmas, gas molecules, rather than the wal1s, as commonly assumed, appear to be the source of "fresh" neutral atoms and protons. This conclusion requires further testing based on model solutions of the rate equations for plasmas under various wall and volume source conditions. This and related work are in progress. 


\section{ACKNOWLEDGEMENT}

This work was supported by $U$. S. Department of Energy, Contract No. EY-76-C-02-3073.

\section{REFERENCES}

[1] S.J.B. Corrigan, J. Chem. Phys., 43, 438 (1965).

\{2\} W. Lesenthal, R.T. Pobiscoe, atru X.A. Zea, Ptrys. Rev., 158, $49(1967)$.

[3] M. Misakian and J.C. Zorn, Phy3. Rev., A6, 2180 (1972).

[4] D. Rapp and P. Englander-Golden, J. Chem. Phys., 43, $1464,(1965)$.

(5) D. Rapp, P. Englander-Golden, and D.D. Briglia, J. Cher. phys., 42, 4081 (1965).

[6] G. H. Dunn and B. van zyl, Phys. Rev., 154, 40 (1967).

[7] A. Crowe and J.w. McConkey, Phys. Rev. Lett., 31, 192 (1973).

[8] R.A. Dandl, et al., Research Program for Plusma Confinement and Heating ìn Elmo Bumpy Torus Devices, ORNL-TM-4941 (1975).

[9] W.L. Stirling, P.M. RYan, C.C. Tsai, and K.N. Leung, Rev. Sci. Instr., 50, 102 (1979); R.C. Davis, T.C. Jernigan, O.B. Morgan, I.D. Stewart, and W.L. stirling, Rev. Sci. Instr., 46, 576 (1975). 
TABLE CAPTIONS

Table 1. The principal reactions of hydrogen molecules with electrons.

Table 2. A listing of the observed atscharge conditions and the corresponding $H_{\alpha}$ profile characteristics. 
TABLE 1

Reactions of Hydrogen Molecules wit' 1 Electrons

Reaction

1. $\mathrm{e}+\mathrm{H} .+\mathrm{H}+\mathrm{H}+\mathrm{C}$

2. $\mathrm{e}_{2}+\mathrm{H}_{2}+\mathrm{H}_{2}^{+}+2 \mathrm{e}$

3. $\mathrm{e}+\mathrm{H}_{2} \rightarrow \mathrm{H}^{+}+\mathrm{H}+2 \mathrm{e}$

4. $\mathrm{e}+\mathrm{H}_{2} \rightarrow \mathrm{H}+\mathrm{H}^{-}$
Name

Nolecular difsociation

(Dissoclatire excitation)

Molecular Ionization

Dissociative Ionization

Dissosiat.ive attachment
Unset Energy

$8.8 \mathrm{eV}$ $(15-18 \mathrm{ev})$

$15.4 \mathrm{eV}$

$18 \mathrm{eV}$

$<1 \mathrm{eV}$ 


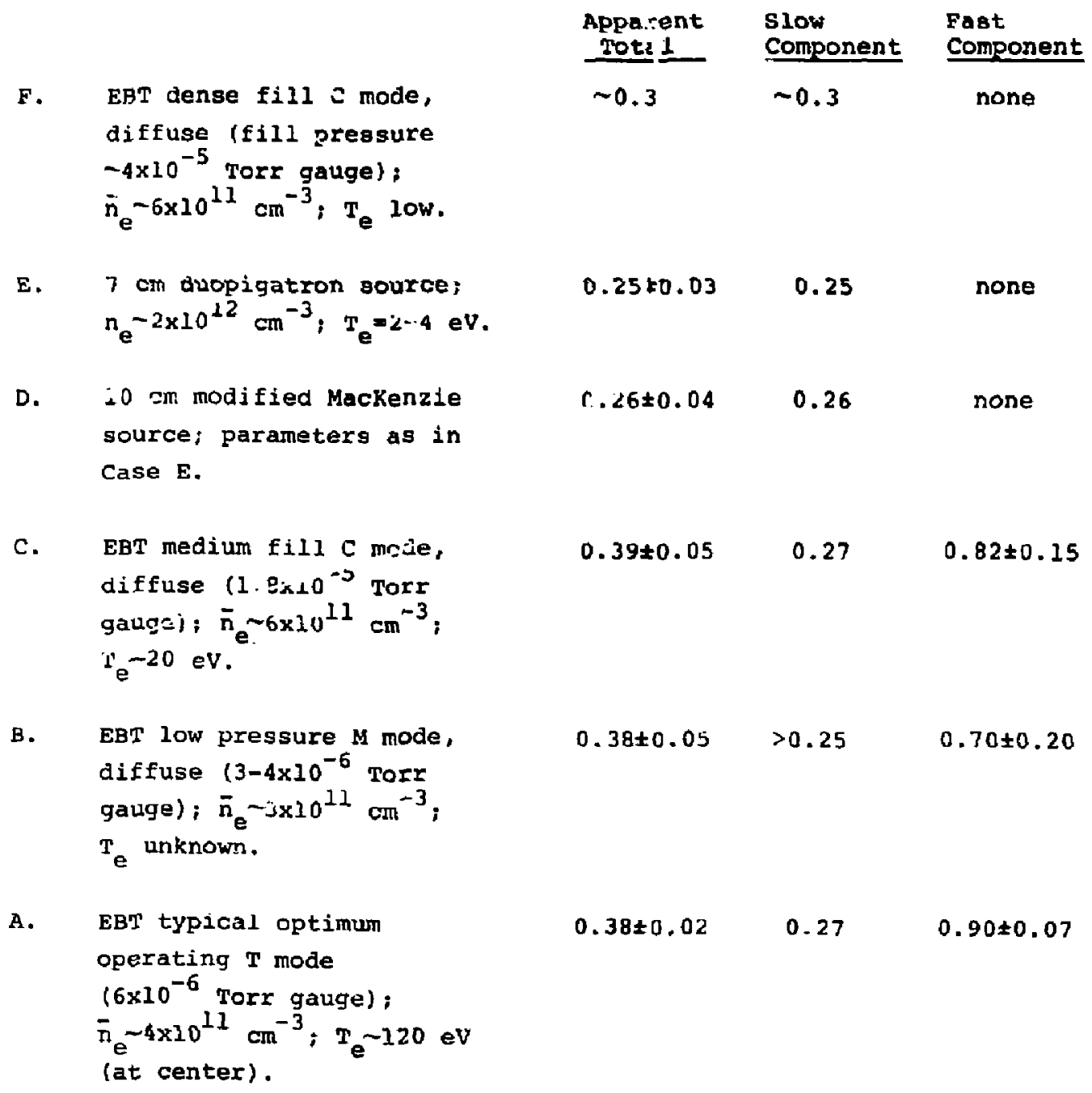

E. $\quad 7 \mathrm{~cm}$ tuopigatron source; $n_{e}-2 \times 10^{12} \mathrm{~cm}^{-3} ; T_{e}=2-4 \mathrm{eV}$.

$0.2510 .03 \quad 0.25 \quad$ none

D. $\quad$ : $0 \mathrm{~m}$ modified Mackenzie

C. $26 \pm 0.04$

0.26

none source: parameterg as in Case E.

c. EBT medium fill c moie, diffuse $\left(1.9 \times 10^{-3}\right.$ Torr

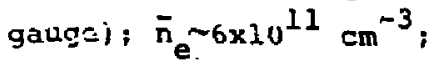
$\mathrm{r}_{\mathrm{e}}^{-20} \mathrm{eV}$.
$0.39 \pm 0.05$
0.27
$0.82 \pm 0.15$

B. EBT low pressure $M$ mode,

diffuse $\left(3-4 \times 10^{-6}\right.$ Torr

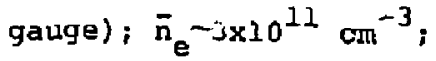

$T_{e}$ unknown.

A. EBT typical optimum $0.38 \pm 0.02 \quad 0.27$ $0.90 \pm 0.07$ operating $T$ mode $\left(6 \times 10^{-6}\right.$ Torr gauge); $\overline{\mathrm{n}} \mathrm{e}^{-4 \times 10^{11}} \mathrm{~cm}^{-3} ; \mathrm{T}^{-120 \mathrm{eV}}$ (at center). 


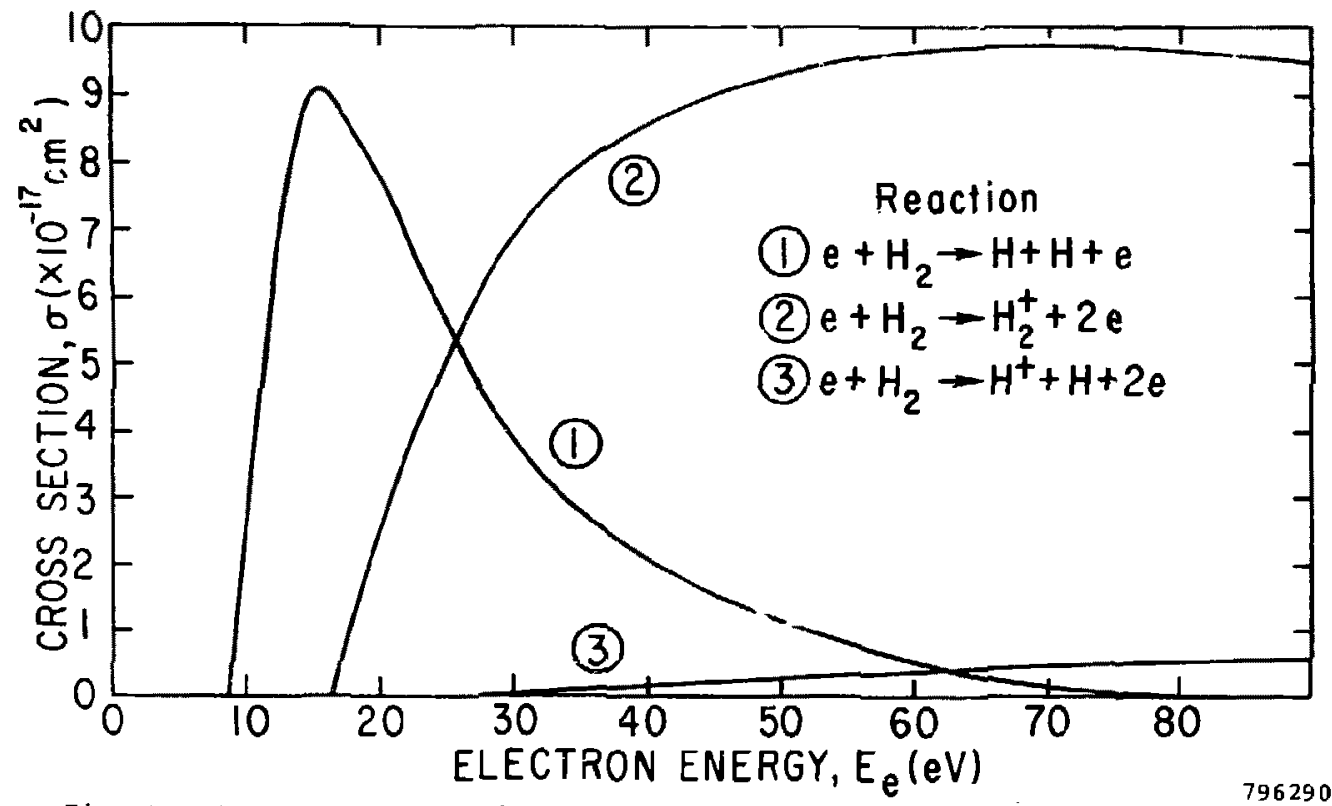

Fig. 1. The cross sections for electron impact (1) molecular dissociation il), (2) molecular ionization [4], and (2) dissociative ionization [5] of $\mathrm{H}_{2}$ as functicns of
the electron energy. 

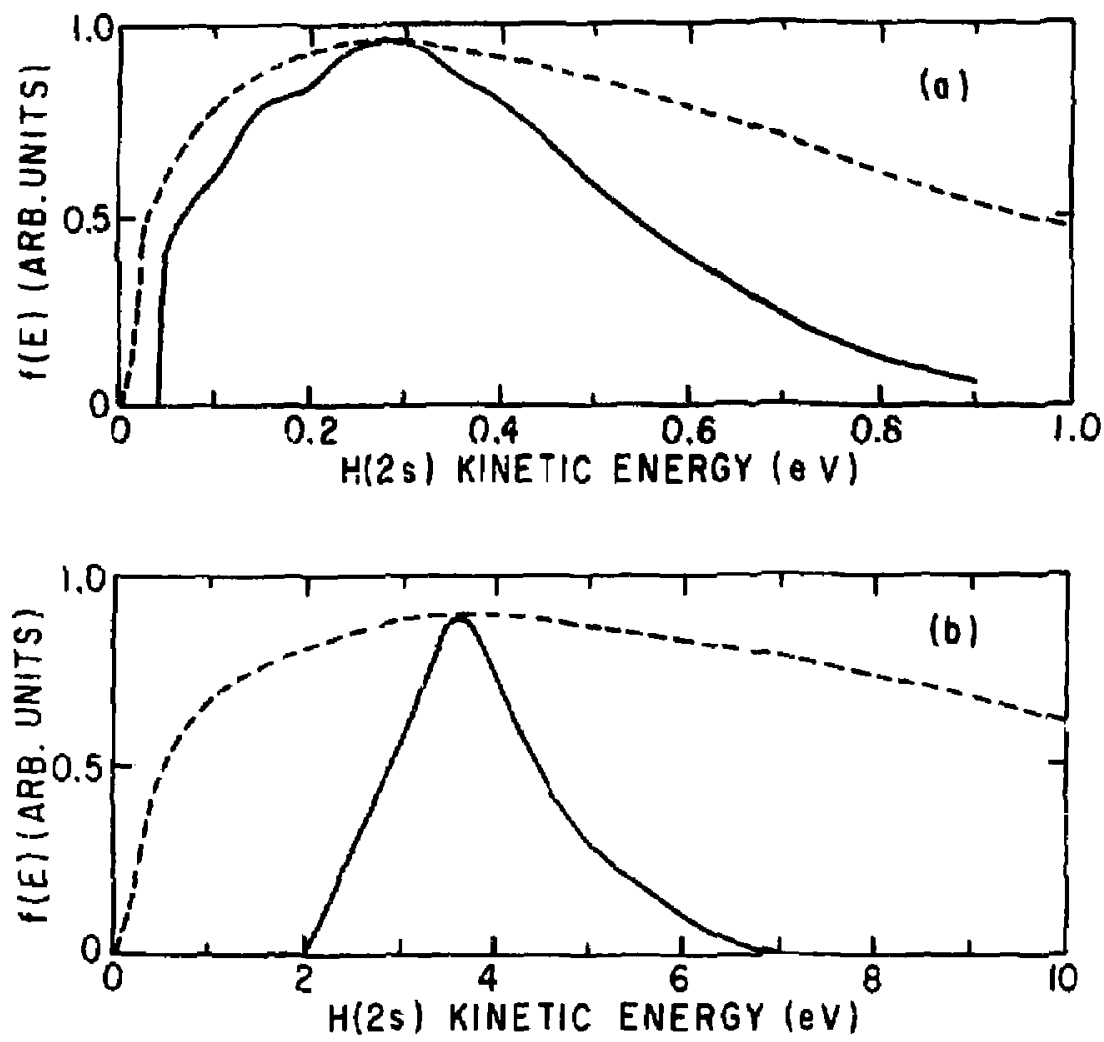

796323

Fig: 2. Experimental time-of-flight measurements of the kinetic energy distributions of slow (a) and fast (b) $H(2 s$ ) dissociative excitation products (solid curves) [3] compared with Maxwellian energy distributions having the same most probable energies (dashed curves). 


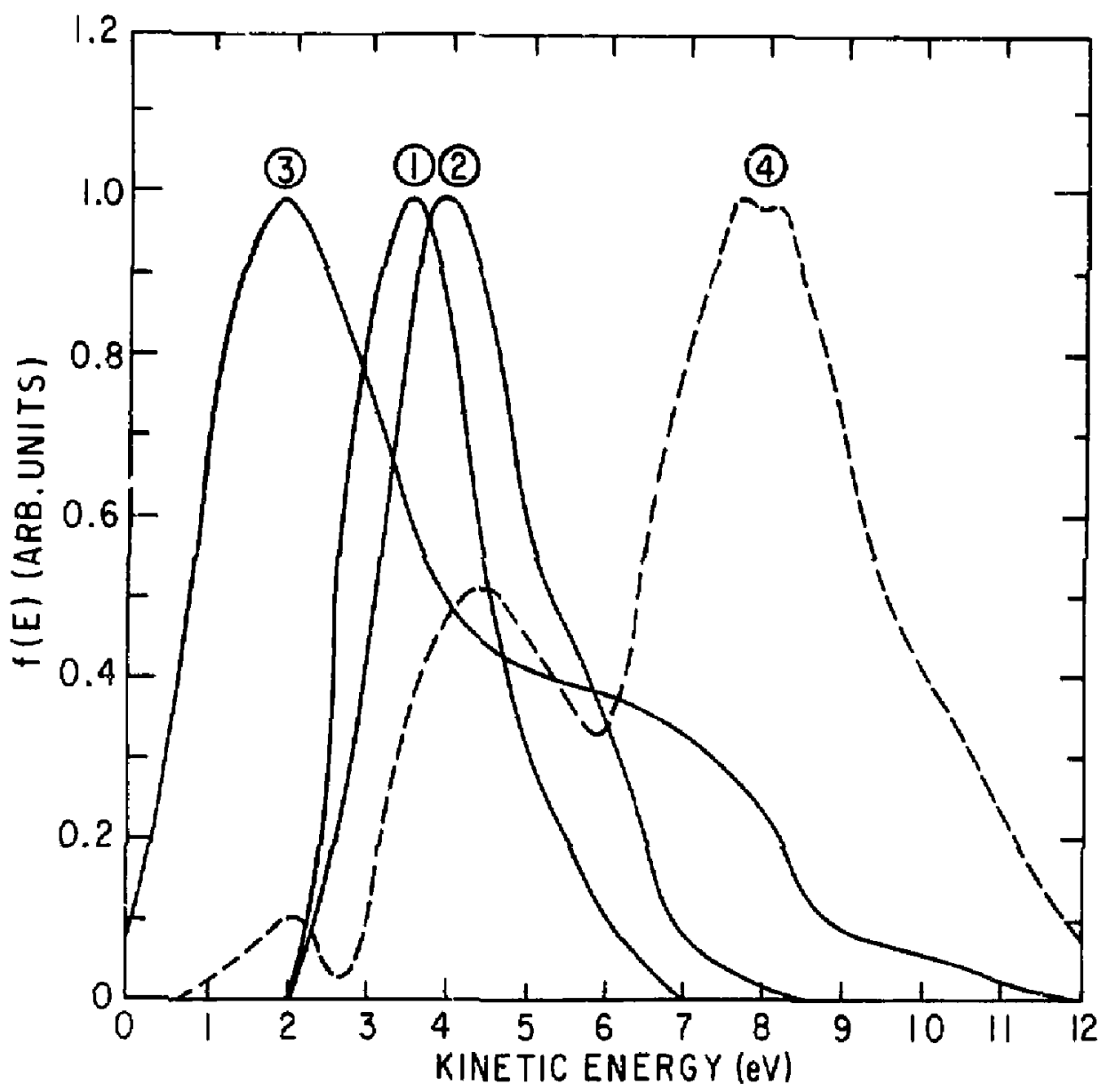

Eig. 3. The kinetic energy distributions of the fast 324 component product particles from various electron impact molecular processes: (1) $H(25)$ from dissociative excitation of $\mathrm{I}_{2}$ by $40 \mathrm{oV}$ electrons, detection at $80^{\circ}$ to electror beam direction [3]: (2) same, with $70 \mathrm{eV}$ electrons (3]) (3) calculated energy of dissociation products from impact of electrons with $\mathrm{E}_{e} \gg 25 \mathrm{eV}$ on $\mathrm{H}_{2}^{+}$ions [6]; and (4) protons from dissociative ianization of $\mathrm{H}_{2}$ by $300 \mathrm{eV}$ electrons [7]. 


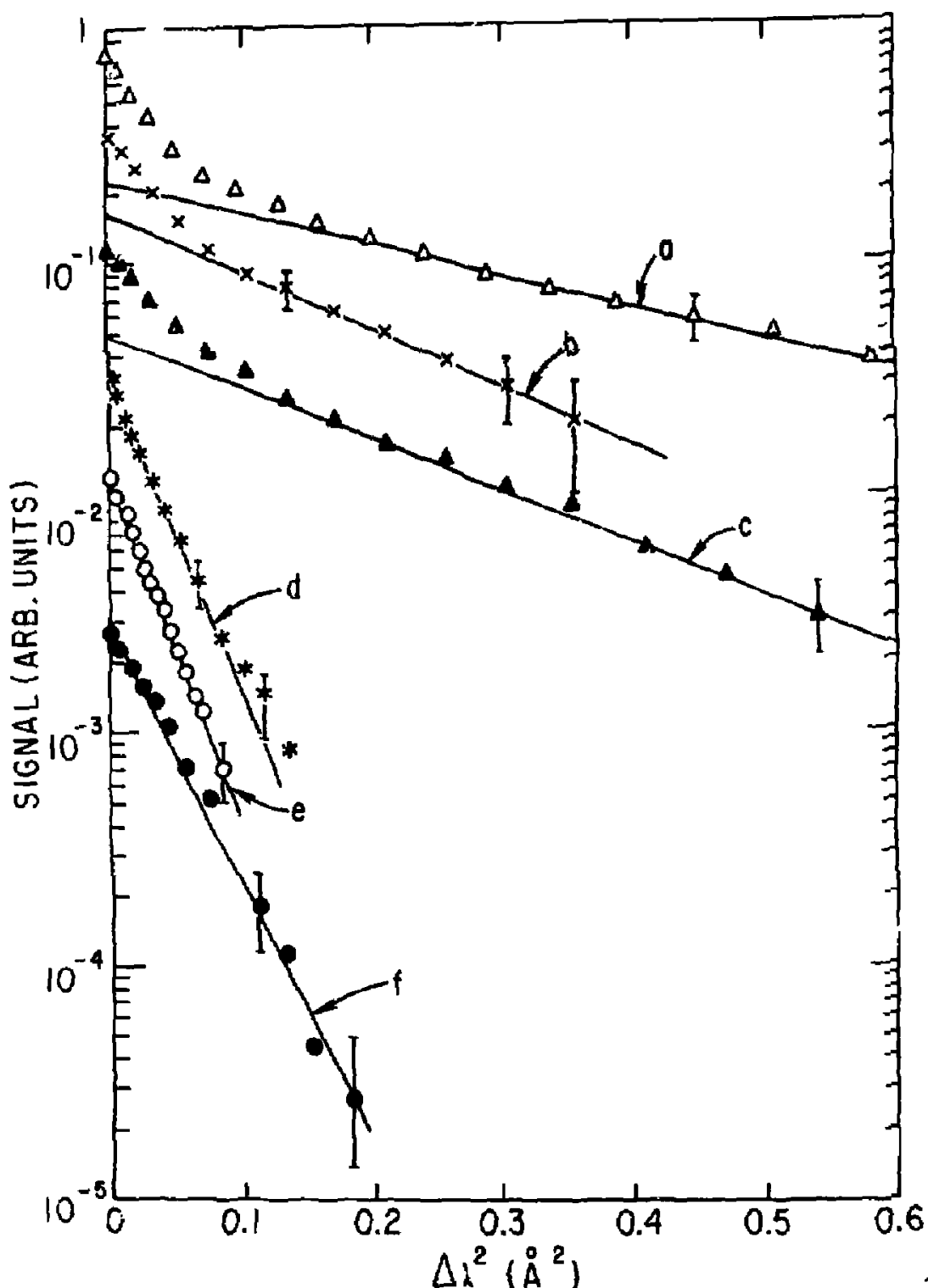

Fig. 4. Raw data fron Fabry-Perot interferometer traces of the $H_{\alpha}$ emission from the plasmas listed in Table 2 (relative signal versus the square of the wavelength shift $\Delta \lambda$ frow the peak intensity point?. 